\title{
Modification of Multiwalled Carbon Nanotubes by Dipyridile Amine for Potentiometric Determination of Lead(II) Ions in Environmental Samples
}

\author{
Hamid Reza Lotfi Zadeh Zhad, Forouzan Aboufazeli, Vahid Amani, \\ Ezzatollah Najafi, and Omid Sadeghi \\ Department of Chemistry, Shahr-e-Rey Branch, Islamic Azad University, P.O. Box 18735-334, Tehran, Iran \\ Correspondence should be addressed to Ezzatollah Najafi; ezzatollah.najafi@gmail.com
}

Received 9 June 2012; Accepted 21 November 2012

Academic Editor: Patricia Valentao

Copyright @ 2013 Hamid Reza Lotfi Zadeh Zhad et al. This is an open access article distributed under the Creative Commons Attribution License, which permits unrestricted use, distribution, and reproduction in any medium, provided the original work is properly cited.

\begin{abstract}
A carbon paste electrode was modified by dipyridile amine functionalized multiwalled carbon nanotubes for determination of trace amounts of lead(II) ions. The electrode composition was graphite powder $70 \%$, paraffin $23 \%$, and dipyridile amine modified MWCNTs 7\% (W/W). The linear range for lead(II) was $9.5 \times 10^{-8}$ to $2.5 \times 10^{-3} \mathrm{~mol} \mathrm{~L}^{-1}$, and the limit of detection was obtained $7.0 \times 10^{-8} \mathrm{~mol} \mathrm{~L}^{-1}$. The lifetime of the electrode was ten weeks, and a fast response time was observed. The electrode was used for determination of trace amounts of $\mathrm{Pb}(\mathrm{II})$ ions in real samples and standard reference materials of water, soil, and plant.
\end{abstract}

\section{Introduction}

As the industries have become widespread, pollution has become a big concern all over the world [2,3]. Determination of heavy metals in environmental samples plays an important role in the monitoring of environmental pollution $[4,5]$. Lead is one of the heavy metals which has attracted lots of researchers interest in environmental protection due to its toxicity [6]. World Health Organization (WHO) has announced the critical level of $\mathrm{Pb}(\mathrm{II})$ ions less than $10 \mu \mathrm{g} \mathrm{L}$ which shows its high toxicity [7]. Continuous exposure to $\mathrm{Pb}$ (II) ions causes dangerous effects to human brain, blood, kidneys, and nervous and reproductive system [8]. Using lead in gasoline antiknock products and paint pigments are the two most widespread uses of this heavy metal. Also it is used in storage batteries, cable sheaths, solder, and radiation shielding [9]. Being an increasing element in environment and being toxic and harmful even at low concentrations are the reasons of developing new methods for determination of lead in environmental samples. There are lots of methods for the determination of $\mathrm{Pb}(\mathrm{II})$ ions in natural samples such as atomic emission spectrometry [10], fluorescence spectrometry [11], potentiometric stripping analysis [12], mass spectrometry [13], and inductively coupled plasma optical emission spectrometry (ICP-OES) [14]. Among these methods, potentiometric methods using ion sensors are common due to their accuracy, high rate, and low cost and also being nondestructive [15]. Potentiometric carbon paste electrodes (CPEs), in comparison to polymeric membrane electrodes, posses very attractive properties such as ease of preparation, renewable surface, stability of their response, low ohmic resistance and no need for internal solution [16, 17]. Introduction of a chemical modifier causes preconcentration of ions on the electrode and increases the methods sensitivity and decreases the detection of limit value [18]. Owing to interesting properties such as ordered structure with high aspect ratio, high surface area, high mechanical and thermal stability, and high electrical conductivity, the usage of carbon nanotubes (CNTs) has been increased recently [1925]. However, in order to be selective, the CNT needs to be modified with an appropriate ligand [26]. In this work, for the first time, multiwalled carbon nanotubes have been modified with dipyridile amine group and used in a sensor for fast determination of $\mathrm{Pb}(\mathrm{II})$ ions in environmental samples. This 
method was validated using several standard reference materials with certified amount of $\mathrm{Pb}$ (II) ions. Also this method was applied for determination of $\mathrm{Pb}$ (II) in natural samples and the results were compared with a previously established method using inductive coupled plasma spectroscopy.

\section{Experimental}

2.1. Regents and Solutions. All analytical grade reagents were persuaded from Merck (Darmstadt, Germany) or Fluka (Buchs, Switzerland) and used without further purification. 2,2'-dipyridylamine was purchased from Sigma-Aldrich company (Missouri, United States). Paraffin oil and lead nitrate were persuaded from Fluka. Carboxyl modified multiwalled carbon nanotube (COOH-MWCNT) with $30 \mu \mathrm{m}$ length and 5-10 $\mathrm{nm}$ in diameter was purchased from Neutrino Company (Tehran, Iran). All other chemicals were purchased from Merck Company and used without further purification. All solutions were made using deionized water, provided from a Milli-Q (Millipore, Bedford, MA, USA) purification system.

2.2. Preparation of Dipyridile Amine Functionalized Multiwalled Carbon Nanotube. For synthesis of dipyridile amine functionalized multiwalled carbon nanotube, in a $250 \mathrm{~mL}$ two-neck round-bottom flask, equipped with a magnetic stir bar and a reflux condenser, $1.0 \mathrm{~g}$ of $\mathrm{COOH}$ MWCNT was suspended in $50 \mathrm{~mL}$ of dried $\mathrm{CH}_{2} \mathrm{Cl}_{2}$ under nitrogen atmosphere. To this solution $10 \mathrm{~mL}$ of oxalyl chloride was slowly added from a dropping funnel. After stirring for $24 \mathrm{~h}, \mathrm{CH}_{2} \mathrm{Cl}_{2}$ was removed under reduced pressure, and the residue was suspended again in $50 \mathrm{~mL}$ of dried methanol. Then $5 \mathrm{~mL}$ of triethylamine and $1 \mathrm{~g}$ of dipyridile amine were added to reaction mixture. After stirring the mixture for $24 \mathrm{~h}$ at room temperature, methanol was removed under reduced pressure and the sorbent was dried at $80^{\circ} \mathrm{C}$ under vacuum. The formation of dipyridile amine functionalized multiwalled carbon nanotube was confirmed by IR spectroscopy, elemental analysis, SEM micrograph, and thermal analysis. A schematic diagram of this synthesis is represented in Figure 1.

2.3. Instruments. A R684 model Analion Ag/AgCl doublejunction reference electrode was used as a reference electrode. A Corning ion analyzer $250 \mathrm{pH} / \mathrm{mV}$ meter was used for the potential measurements. The $\mathrm{pH}$ meter was a digital WTW Metrohm 827 Ion analyzer (Herisau, Switzerland) equipped with a combined glass-calomel electrode. All measurements were made at $25 \pm 1^{\circ} \mathrm{C}$. Thermal gravimetric and differential thermal analysis (TG/DTA) was carried out on a Bahr STA-503 instrument (Germany) under air atmosphere. IR spectra were recorded by BOMEM/MB series Spectrometer (Quebec, Canada). The Elemental analysis was performed with a Thermo Finnigan Flash-2000 microanalyzer (Neolab, Italy). Morphology and size of the particles were observed on a Philips S-4160 scanning electron microscope (SEM) (Eindhoven, The Netherlands) with gold coating.

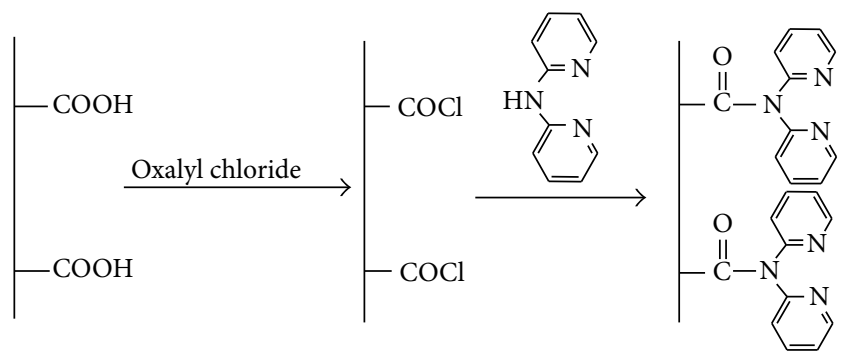

FIGURE 1: A schematic diagram for modification of MWCNT with dipyridile amine.

2.4. Preparation of Modified Carbon Paste Electrode. The chemically modified carbon paste electrodes were prepared by thoroughly mixing a mixture that contains graphite powder $70 \%$, paraffin $23 \%$, and dipyridile amine modified MWCNTs 7\% (W/W). The electrode body was fabricated from a glass tube of i.d. $5 \mathrm{~mm}$ and a height of $3 \mathrm{~cm}$. After the mixture homogenization, the paste was packed carefully into the tube tip to avoid possible air gaps, often enhancing the electrode resistance. A copper wire was inserted into the opposite end to establish electrical contact. The external electrode surface was smoothed with a soft paper. A new surface was produced by scraping out the old surface and replacing the carbon paste.

2.5. Electrode Conditioning. The electrode surfaces were conditioned by $1.0 \times 10^{-4} \mathrm{~mol} \mathrm{~L}^{-1} \mathrm{~Pb}\left(\mathrm{NO}_{3}\right)_{2}$ and $1.0 \times$ $10^{-3} \mathrm{~mol} \mathrm{~L}^{-1} \mathrm{NaNO}_{3}$ for 24 hours. The $\mathrm{pH}$ of the solution was adjusted to 6 by acetate buffer $\left(0.01 \mathrm{~mol} \mathrm{~L}^{-1}\right)$. The electrodes were rinsed by deionized water before potentiometric measurements.

2.6. Emf Measurements. All measurements were done versus $\mathrm{Ag}, \mathrm{AgCl}(\mathrm{s})$ reference electrode. The $\mathrm{pH}$ was adjusted to 6 by acetate buffer with concentration of $0.01 \mathrm{~mol} \mathrm{~L}^{-1}$.

The electrochemical cell can be represented as follows:

$\mathrm{Ag}, \mathrm{AgCl}(\mathrm{s}), \mathrm{KCl}\left(3 \mathrm{~mol} \mathrm{~L}^{-1}\right) \|$ analyte solution | carbon paste electrode.

2.7. Sample Preparation. A drinking water sample (ERMCA022) was obtained from Chemistry Reference Laboratory Equipment (Turkey) and used without any treatment. Water samples were obtained from tap water (Tehran, Iran), distilled water, and sea water (Caspian Sea, Sari, Iran).

The soil standard reference material (CRM-SA-C (sandy soil)) obtained from Environmental Express Company (Charleston, South Carolina) was digested in an $8 \mathrm{~mL}$ mixture of $5 \%$ aqua regia with the assistance of a microwave digestion system. Digestion was carried out for $2 \mathrm{~min}$ at $250 \mathrm{~W}, 2 \mathrm{~min}$ at $0 \mathrm{~W}, 6 \mathrm{~min}$ at $250 \mathrm{~W}, 5 \mathrm{~min}$ at $400 \mathrm{~W}$, and $8 \mathrm{~min}$ at $550 \mathrm{~W}$, and the mixture was then vented for $8 \mathrm{~min}$, and the residue from this digestion was then diluted with deionized water. Finally, this method was applied for determination of lead from the aforementioned water samples. Soil samples were 
TABLE 1: Optimization of the electrode composition.

\begin{tabular}{|c|c|c|c|c|c|c|c|c|}
\hline Electrode no. & $\begin{array}{c}\text { Graphite } \\
\text { powder (\%) }\end{array}$ & $\begin{array}{c}\text { Paraffin } \\
(\%)\end{array}$ & $\begin{array}{l}\text { Di-pyridile } \\
\text { amine }\end{array}$ & $\begin{array}{c}\text { Unmodified } \\
\text { MWCNTs } \\
(\%)\end{array}$ & $\begin{array}{l}\text { Modified } \\
\text { MWCNTs } \\
(\%)\end{array}$ & $\begin{array}{l}\text { Slope } \\
(\mathrm{mV})\end{array}$ & Linear range $\left(\mathrm{mol} \mathrm{L}^{-1}\right)$ & $R^{2}$ \\
\hline 1 & 75 & 25 & 0 & 0 & 0 & $11.9 \pm 3.1$ & - & - \\
\hline 2 & 73 & 24 & 3 & 0 & 0 & $15.6 \pm 2.2$ & $3.5 \times 10^{-6}$ to $1.0 \times 10^{-2}$ & 0.915 \\
\hline 3 & 72 & 23 & 5 & 0 & 0 & $19.3 \pm 1.9$ & $1.0 \times 10^{-6}$ to $1.0 \times 10^{-2}$ & 0.935 \\
\hline 4 & 71 & 22 & 7 & 0 & 0 & $18.5 \pm 1.9$ & $1.5 \times 10^{-6}$ to $1.0 \times 10^{-2}$ & 0.928 \\
\hline 5 & 73 & 24 & 0 & 3 & 0 & $13.5 \pm 2.1$ & $5.0 \times 10^{-6}$ to $1.0 \times 10^{-2}$ & 0.905 \\
\hline 6 & 72 & 23 & 0 & 5 & 0 & $16.9 \pm 1.8$ & $2.0 \times 10^{-6}$ to $1.0 \times 10^{-2}$ & 0.919 \\
\hline 7 & 70 & 23 & 0 & 7 & 0 & $20.2 \pm 1.7$ & $8.0 \times 10^{-7}$ to $5.0 \times 10^{-3}$ & 0.946 \\
\hline 8 & 68 & 23 & 0 & 9 & 0 & $18.8 \pm 1.9$ & $1.5 \times 10^{-6}$ to $1.0 \times 10^{-2}$ & 0.939 \\
\hline 9 & 72 & 23 & 5 & 5 & 0 & $25.0 \pm 1.7$ & $3.5 \times 10^{-7}$ to $2.5 \times 10^{-3}$ & 0.975 \\
\hline 10 & 67 & 23 & 5 & 7 & 0 & $28.9 \pm 1.1$ & $7.5 \times 10^{-8}$ to $2.5 \times 10^{-3}$ & 0.995 \\
\hline 11 & 65 & 23 & 5 & 9 & 0 & $27.8 \pm 1.5$ & $1.5 \times 10^{-7}$ to $2.5 \times 10^{-3}$ & 0.979 \\
\hline 12 & 73 & 24 & 0 & 0 & 3 & $24.7 \pm 1.7$ & $5.0 \times 10^{-7}$ to $2.5 \times 10^{-3}$ & 0.966 \\
\hline 13 & 72 & 23 & 0 & 0 & 5 & $26.3 \pm 1.5$ & $2.0 \times 10^{-7}$ to $2.5 \times 10^{-3}$ & 0.970 \\
\hline 14 & 70 & 23 & 0 & 0 & 7 & $28.6 \pm 1.2$ & $9.5 \times 10^{-8}$ to $2.5 \times 10^{-3}$ & 0.990 \\
\hline 15 & 67 & 23 & 0 & 0 & 9 & $28.0 \pm 1.3$ & $1.0 \times 10^{-7}$ to $2.5 \times 10^{-3}$ & 0.982 \\
\hline
\end{tabular}

also collected randomly from a depth of approximately $1 \mathrm{~cm}$ in different place in Tehran, Iran.

NIST 1572 (Citrus leaves) standard reference material was obtained from National Institute of Standards and Technology (USA). In order to digest these leaves, after washing with distilled water, $1.0 \mathrm{~g}$ of it was grounded and dried out at $80^{\circ} \mathrm{C}$ and triturated in a porcelain mortar. After sieving, the particles with sizes less than $20 \mu \mathrm{m}$ were dissolve in $1 \mathrm{~mL}$ of $3 \mathrm{~mol} \mathrm{~L}^{-1} \mathrm{HNO}_{3}$ solution and diluted with distilled water to $10 \mathrm{~mL}$. The leaf sampling was carried out in spring of 2012 from Cedrus trees in different places in Tehran, Iran.

\section{Results and Discussion}

The response of a potentiometric carbon paste electrode is affected by conductivity of the electrode and selectivity of the chelating agent to the analyte. The conductivity can be improved by adding conductive materials like MWCNTs. Choosing a selective chelating agent like dipyridile amine can improve the electrode selectivity, respecting adsorption of soft acid $\mathrm{Pb}^{2+}$ ion and soft base of dipyridile amine. The lifetime of paste electrode is affected by stability of the electrode composition. By stabilizing dipyridile amine on the surface of MWCNTs, the lifetime of the electrode was improved.

\subsection{Dipyridile Amine Functionalized Multiwalled Carbon} Nanotube Characterization. A schematic diagram of this synthesis is represented in Figure 1. The formation of dipyridile amine functionalized multiwalled carbon nanotube was confirmed by IR spectroscopy, elemental analysis, SEM micrograph, and thermal analysis. IR $\left(\mathrm{KBr}, \mathrm{cm}^{-1}\right)$ : $3440(\mathrm{NH}), 3037$ (CH, aromatic), 2983 (CH, aliphatic), 1653 (C=N pyridine), 1607 (C=C pyridine), 890 (MWCNT).

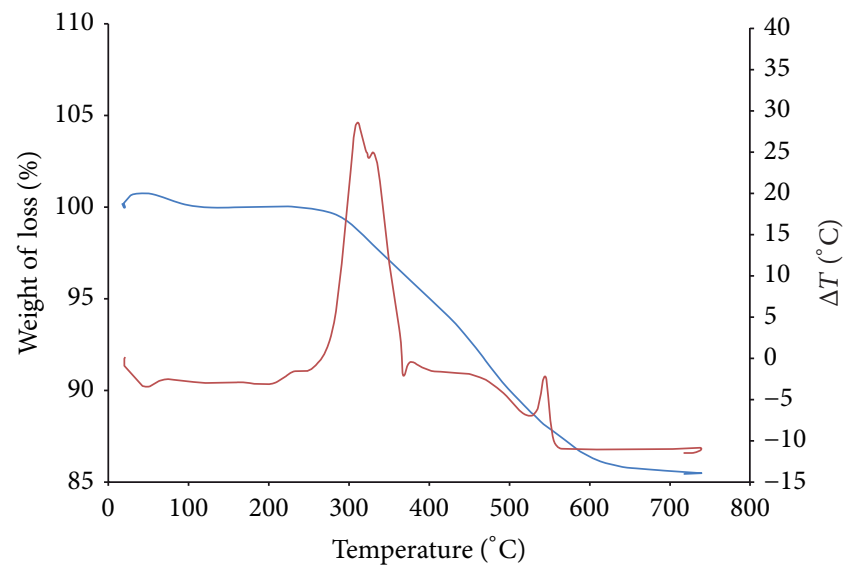

Figure 2: TG-DTA diagram of dipyridile amine MWCNT.

According to elemental analysis results $(\mathrm{C}, 9.42 ; \mathrm{H}, 0.81 ; \mathrm{N}$, $3.31 \%$ ), the dipyridile amine concentration on the surface of this sorbent is $136 \mathrm{mg} \mathrm{g}^{-1}$. The thermal analysis of this composite confirmed the elemental analysis results as there is approximately $13 \%$ weight reduction in TG curve. Also the DTA curve showed that this composite is stable up to $230^{\circ} \mathrm{C}$ (Figure 2). Finally, the SEM micrograph of this composite shows the nanostructure of dipyridile amine functionalized multiwalled carbon nanotube (Figure 3).

3.2. Electrode Composition. Since the electrode composition is the most important factor in the responses and selectivity of the electrode, different amounts of graphite powder, paraffin oil, unmodified MWCNTs, dipyridile amine, and modified MWCNTs were thoroughly mixed, and the responses were studied and listed in Table 1. In the first study no MWCNTs 


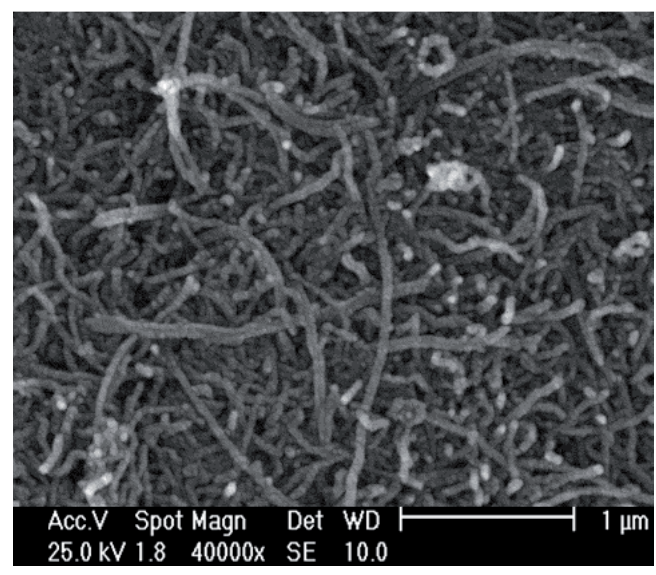

FIGURE 3: SEM micrograph of dipyridile amine MWCNT.

and dipyridile amine were added to the electrode (electrode no. 1). Then some amounts of dipyridile amine were added to the electrode, and interaction of dipyridile amine with lead ions improved the electrode performance (electrode no. 2-4). The influence of adding unmodified MWCNTs in the electrode performance was studied in electrode no. 5-8. In electrode no. 9-11, a mixture of dipyridile amine and unmodified MWCNTs was used, and a Nernstian slope of $28.9 \mathrm{mV}$ in a linear range of $7.5 \times 10^{-8}$ to $2.5 \times 10^{-3} \mathrm{~mol} \mathrm{~L}^{-1}$ was observed in electrode no. 10. In electrode no. 12-15, modified MWCNTs were added to the electrode, and in electrode no. 14 a Nernstian slope of $28.6 \mathrm{mV}$ in a linear range of $9.5 \times 10^{-8}$ to $2.5 \times 10^{-3} \mathrm{~mol} \mathrm{~L}^{-1}$ was observed. In the next studies, electrode no. 14 with the composition of graphite powder $70 \%$, paraffin $23 \%$ and modified MWCNTs $7 \%(\mathrm{~W} / \mathrm{W})$ was chosen as the optimum composition and its performance was compared to the electrodes no. 10 with the composition of graphite powder $67 \%$, paraffin $23 \%$, dipyridile amine 5\%, and unmodified MWCNTs 7\% (W/W).

3.3. Calibration Curve. For quantitative determination of $\mathrm{Pb}(\mathrm{II})$ ions, a calibration curve in the linear range of $9.5 \times 10^{-8}$ to $2.5 \times 10^{-3} \mathrm{~mol} \mathrm{~L}^{-1}$ was drawn versus measurements of Emf by electrode no. 14 . The standard deviation for ten replicates is $1.2 \mathrm{mV}$. Results were shown in Figure 4. By extrapolating the linear parts of the ion selective calibration curve, the detection limit of the electrode was calculated to be $7.0 \times$ $10^{-8} \mathrm{~mol} \mathrm{~L}^{-1}[1,27]$.

3.4. Influences of $\mathrm{pH}$. For investigation of $\mathrm{pH}$ independent range of electrode no. 14, its potential response at concentration of $\mathrm{Pb}$ (II) ion $\left(1.0 \times 10^{-5} \mathrm{M}\right)$ in a wide $\mathrm{pH}$ range (2.0-9.0) was measured. Various $\mathrm{pH}$ adjustments were done using concentrated $\mathrm{HNO}_{3}$ or $\mathrm{NaOH}$. The potential response as a function of $\mathrm{pH}$ value is depicted in Figure 5. As it is seen, the potential response of the $\mathrm{Pb}(\mathrm{II})$ electrode is almost constant between $\mathrm{pH}$ (5-7), and in this $\mathrm{pH}$ range, no interference from $\mathrm{H}_{3} \mathrm{O}^{+}$in acidic $\mathrm{pH}$ or $\mathrm{OH}^{-}$in basic $\mathrm{pH}$ is observed. The $\mathrm{pH}=6$ was chosen as the optimum $\mathrm{pH}$ for all measurements. The effect of $\mathrm{pH}$ on electrode no. 10 was similar to electrode

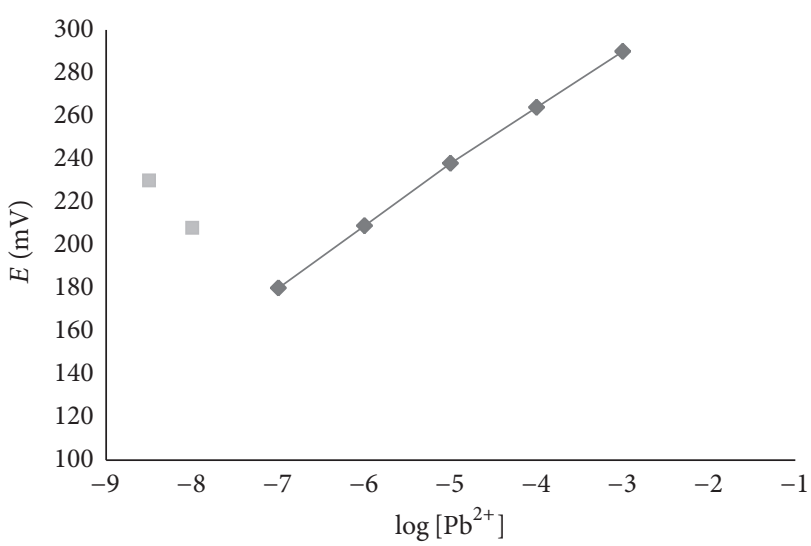

FIgURE 4: The calibration curve for $\mathrm{Pb}(\mathrm{II})$ ion, $\mathrm{pH}=6$.

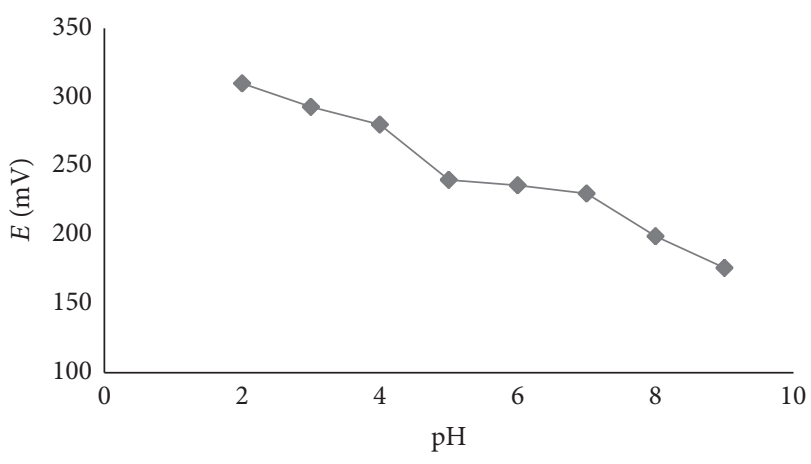

FIgURE 5: Influence of $\mathrm{pH}$ on electrode response to lead(II).

TABLE 2: Matched potential selectivity coefficient for interfering cations.

\begin{tabular}{lc}
\hline Interfering ions $(X)$ & $k_{\mathrm{Hg}, X}^{\mathrm{MPM}}$ \\
\hline $\mathrm{Na}^{+}$ & $2.1 \times 10^{-4}$ \\
$\mathrm{~K}^{+}$ & $8.4 \times 10^{-4}$ \\
$\mathrm{Cs}^{+}$ & $3.1 \times 10^{-3}$ \\
$\mathrm{Ca}^{2+}$ & $6.3 \times 10^{-4}$ \\
$\mathrm{Mg}^{2+}$ & $7.7 \times 10^{-4}$ \\
$\mathrm{Cd}^{2+}$ & $4.3 \times 10^{-3}$ \\
$\mathrm{Ni}^{2+}$ & $8.1 \times 10^{-3}$ \\
$\mathrm{Cu}^{2+}$ & $2.9 \times 10^{-3}$ \\
$\mathrm{Cr}^{3+}$ & $7.4 \times 10^{-3}$ \\
$\mathrm{Fe}^{3+}$ & $4.5 \times 10^{-3}$ \\
$\mathrm{Ag}^{+}$ & $7.8 \times 10^{-3}$ \\
$\mathrm{Zn}^{2+}$ & $8.3 \times 10^{-3}$ \\
\hline
\end{tabular}

no. 14 which should be related to presence of dipyridile amine in the electrode composition.

3.5. Study of Response Time. The average static response time was defined as the required time for the sensors to reach a potential of $90 \%$ of the final equilibrium values, after successive immersions in a series of solutions, each having a 10 -fold concentration difference $[1,27]$. The $\mathrm{Pb}$ (II) concentration was changed in the liner range, and the results 
TABLE 3: The lifetime of the electrode no. 14 and electrode no. 10. The results are based on triplicate measurements.

\begin{tabular}{lcccc}
\hline \multirow{2}{*}{ Week } & \multicolumn{2}{c}{ Electrode no. 14 } & \multicolumn{2}{c}{ Electrode no. 10} \\
& Slope $(\mathrm{mV})$ & Detection limit $\left(\mathrm{mol} \mathrm{L}^{-1}\right)$ & Slope $(\mathrm{mV})$ & ${\text { Detection limit }\left(\mathrm{mol} \mathrm{L}^{-1}\right)}^{-8}$ \\
\hline First & 28.6 & $7.0 \times 10^{-8}$ & 28.9 & $4.5 \times 10^{-8}$ \\
Second & 28.5 & $7.5 \times 10^{-8}$ & 27.5 & $1.9 \times 10^{-7}$ \\
Third & 28.3 & $8.1 \times 10^{-8}$ & 25.1 & $5.9 \times 10^{-7}$ \\
Fourth & 28.0 & $9.6 \times 10^{-8}$ & 16.2 & - \\
Fifth & 27.7 & $2.0 \times 10^{-7}$ & - & - \\
Sixth & 27.1 & $5.1 \times 10^{-7}$ & - & - \\
Seventh & 26.7 & $8.1 \times 10^{-7}$ & - & - \\
Eighth & 26.1 & $8.9 \times 10^{-7}$ & - & - \\
Ninth & 25.6 & $9.5 \times 10^{-7}$ & - & - \\
Tenth & 25.2 & $1.3 \times 10^{-6}$ & - \\
Eleventh & 22.1 & - & -
\end{tabular}

TABLE 4: Recovery of determination of $\mathrm{Pb}(\mathrm{II})$ ions in certified reference materials.

\begin{tabular}{|c|c|c|c|c|c|c|}
\hline \multirow{2}{*}{ Sample } & \multirow{2}{*}{ Unit } & \multicolumn{2}{|c|}{ Concentration } & \multirow{2}{*}{ Added } & \multirow{2}{*}{ Found } & \multirow{2}{*}{ Recovery (\%) } \\
\hline & & Certified & Found & & & \\
\hline ERM-CA022 (drinking water) & $\mu \mathrm{g} \mathrm{L}^{-1}$ & $26 \pm 0.9$ & 24.9 & - & - & 95.8 \\
\hline CRM-SA-C (sandy soil) & $\mathrm{mg} \mathrm{kg}^{-1}$ & $133.0 \pm 0.6$ & 128.3 & - & - & 96.4 \\
\hline NIST 1572 (citrus leaves) & $\mathrm{mg} \mathrm{kg}^{-1}$ & $13.3 \pm 2.4$ & 13.1 & - & - & 98.4 \\
\hline Tap water & $\mu \mathrm{g} \mathrm{Kg}^{-1}$ & ND & ND & 20.0 & 19.9 & 99.7 \\
\hline Distilled water & $\mu \mathrm{g} \mathrm{Kg}^{-1}$ & ND & ND & 20.0 & 19.8 & 99.4 \\
\hline Sea water & $\mu \mathrm{g} \mathrm{Kg}^{-1}$ & ND & ND & 20.0 & 19.6 & 98.3 \\
\hline North soil & $\mu \mathrm{g} \mathrm{Kg}^{-1}$ & $47.1^{\mathrm{a}}$ & 46.2 & 20.0 & 63.7 & 96.2 \\
\hline South soil & $\mu \mathrm{g} \mathrm{Kg}^{-1}$ & $64.7^{\mathrm{a}}$ & 64.2 & 20.0 & 81.8 & 97.1 \\
\hline North leaves & $\mu \mathrm{g} \mathrm{Kg}^{-1}$ & $27.4^{\mathrm{a}}$ & 27.2 & 20.0 & 46.6 & 98.6 \\
\hline South leaves & $\mu \mathrm{g} \mathrm{Kg}^{-1}$ & $31.9^{\mathrm{a}}$ & 31.8 & 20.0 & 51.1 & 98.5 \\
\hline
\end{tabular}

${ }^{\mathrm{a}}$ Certified by previously established method [1].

were studied. The results showed that the response time for the proposed electrode is 50 seconds. The same procedure was performed with electrode no. 10, and the response time was evaluated to be 3 minutes. The fast response time of electrode no. 14 might be as a result of presence of dipyridile on the surface of MWCNTs.

3.6. Influence of Interference Ions. Matched potential method (MPM) is the recommended method for studying influence of interferences ions in ion selective electrodes by IUPAC [28]. The method is based on measuring the specific activity of the primary ion which is added to a reference solution. In this study the interfering ions were successively added to an identical reference solution with concentration of $5.0 \times 10^{-7} \mathrm{~mol} \mathrm{~L}^{-1}$, until the measured potential matched to obtained value before adding the primary ions. Then matched potential selectivity coefficient, $k_{\mathrm{Pb}, X}^{\mathrm{MPM}}$, is calculated from the resulting primary ion to the interfering ion activity ratio, $k_{\mathrm{Pb}, X}^{\mathrm{MPM}}=\Delta\left(a_{\mathrm{Hg}} / a_{x}\right)$ [29]. The interference of $\mathrm{Na}^{+}, \mathrm{K}^{+}, \mathrm{Cs}^{+}$, $\mathrm{Ca}^{2+}, \mathrm{Mg}^{2+}, \mathrm{Cd}^{2+}, \mathrm{Ni}^{2+}, \mathrm{Cu}^{2+}, \mathrm{Cr}^{3+}, \mathrm{Fe}^{3+}, \mathrm{Ag}^{+}$, and $\mathrm{Zn}^{2+}$ was investigated and showed that they have no significant effect on the response to $\mathrm{Pb}^{2+}$. The $k_{\mathrm{Pb}, X}^{\mathrm{MPM}}$ values for the interferences are shown in Table 2. The effect of interference ions on electrode no. 10 was also studied, and similar selectivity to electrode no. 14 was observed which should be related to selectivity of dipyridile amine with lead ions.

3.7. Lifetime. The lifetime of an electrode is the period of time that the electrode shows no changes in the efficiency of the measurements. To study this factor, the electrode was calibrated periodically with standard lead solutions. Then the electrode was conditioned and calibrated in the next week. As the results in Table 3 show, the lifetime of the electrode was evaluated to be ten weeks. The lifetime of the electrode no. 10 was evaluated to be four weeks. The long lifetime period of electrode no. 14 may be due to stability of dipyridile amine on the surface of MWCNTs.

3.8. Method Validation. Different type of standard reference materials (water, soil, and plant) was used for validation of this method. The samples were digested by mentioned method, and the $\mathrm{Pb}(\mathrm{II})$ contents were analysed by this method. As it can be seen in Table 4, the results have good compatibility with certified ones. Moreover after validation of method by standard references materials, this method was applied for determination of $\mathrm{Pb}$ (II) concentrations in different environmental samples, and the results were compared to 
previously established method for determination of lead ions by inductive coupled plasma spectroscopy reported by Li et al. [30]. Being accurate and precise, this method could be a sensitive and confidence method for determination of lead in various environmental samples such as soil, water, and plants.

\section{Conclusion}

Two carbon paste electrodes were developed for determination of lead ions. In one electrode the performance of the electrode was improved by adding MWCNTs and dipyridile amine. In the other electrode dipyridile was chemically modified on the surface of MWCNTs and added to the electrode as a modifier, and the performance of the second electrode was improved in terms of response time and lifetime. Method validation was done by analysis of standard reference materials with a matrix of water, soil, and plant.

\section{References}

[1] V. K. Gupta and A. K. Singh B, "A cerium(III) selective polyvinyl chloride membrane sensor based on a Schiff base complex of N,N-bis[2-(salicylideneamino)ethyl]ethane1,2-diamine," Analytica Chimica Acta, vol. 575, no. 2, pp. 198-204, 2006.

[2] M. Tüzen, "Determination of heavy metals in soil, mushroom and plant samples by atomic absorption spectrometry," Microchemical Journal, vol. 74, no. 3, pp. 289-297, 2003.

[3] M. C. Yebra-Biurrun, S. Cancela-Pérez, and A. Moreno-CidBarinaga, "Coupling continuous ultrasound-assisted extraction, preconcentration and flame atomic absorption spectrometric detection for the determination of cadmium and lead in mussel samples," Analytica Chimica Acta, vol. 533, no. 1, pp. 51-56, 2005.

[4] J. Sastre, A. Sahuquillo, M. Vidal, and G. Rauret, "Determination of $\mathrm{Cd}, \mathrm{Cu}, \mathrm{Pb}$ and $\mathrm{Zn}$ in environmental samples: microwave-assisted total digestion versus aqua regia and nitric acid extraction," Analytica Chimica Acta, vol. 462, no. 1, pp. 59-72, 2002.

[5] G. Jia, M. Belli, M. Blasi, A. Marchetti, S. Rosamilia, and U. Sansone, "210Pb and 210Po determination in environmental samples," Applied Radiation and Isotopes, vol. 53, no. 1-2, pp. 115-120, 2000.

[6] O. Dalman, A. Demirak, and A. Balci, "Determination of heavy metals $(\mathrm{Cd}, \mathrm{Pb})$ and trace elements $(\mathrm{Cu}, \mathrm{Zn})$ in sediments and fish of the Southeastern Aegean Sea (Turkey) by atomic absorption spectrometry," Food Chemistry, vol. 95, no. 1, pp. 157-162, 2006.

[7] P. Liang and H. Sang, "Determination of trace lead in biological and water samples with dispersive liquid-liquid microextraction preconcentration," Analytical Biochemistry, vol. 380, no. 2, pp. 21-25, 2008.

[8] D. Citak and M. Tuzen, "A novel preconcentration procedure using cloud point extraction for determination of lead, cobalt and copper in water and food samples using flame atomic absorption spectrometry," Food and Chemical Toxicology, vol. 48, no. 5, pp. 1399-1404, 2010.

[9] A. Sabarudin, N. Lenghor, Y. Liping, Y. Furusho, and S. Motomizu, "Automated online preconcentration system for the determination of trace amounts of lead using $\mathrm{Pb}$-selective resin and inductively coupled plasma-atomic emission spectrometry," Spectroscopy Letters, vol. 39, no. 6, pp. 669-682, 2006.

[10] K. Prasad, P. Gopikrishna, R. Kala, T. P. Rao, and G. R. K. Naidu, "Solid phase extraction vis-à-vis coprecipitation preconcentration of cadmium and lead from soils onto 5,7dibromoquinoline-8-ol embedded benzophenone and determination by FAAS," Talanta, vol. 69, no. 4, pp. 938-945, 2006.

[11] O. W. Lau and S. Y. Ho, "Simultaneous determination of traces of iron, cobalt, nickel, copper, mercury and lead in water by energy-dispersive $\mathrm{x}$-ray fluorescence spectrometry after preconcentration as their piperazino-1,4-bis(dithiocarbamate) complexes," Analytica Chimica Acta, vol. 280, no. 2, pp. 269-277, 1993.

[12] D. Jagner, M. Josefson, and S. Westerlund, "Determination of zinc, cadmium, lead and copper in sea water by means of computerized potentiometric stripping analysis," Analytica Chimica Acta, vol. 129, pp. 153-161, 1981.

[13] T. De Smaele, L. Moens, R. Dams, P. Sandra, J. Van Der Eycken, and J. Vandyck, "Sodium tetra(n-propyl)borate: a novel aqueous in situ derivatization reagent for the simultaneous determination of organomercury, -lead and -tin compounds with capillary gas chromatography-inductively coupled plasma mass spectrometry," Journal of Chromatography A, vol. 793, no. 1, pp. 99-106, 1998.

[14] V. A. Lemos and S. L. C. Ferreira, "On-line preconcentration system for lead determination in seafood samples by flame atomic absorption spectrometry using polyurethane foam loaded with 2-(2-benzothiazolylazo)-2-p-cresol," Analytica Chimica Acta, vol. 441, pp. 281-289, 2001.

[15] L. Gil, J. M. Barat, I. Escriche, E. Garcia-Breijo, R. MartínezMáñez, and J. Soto, "An electronic tongue for fish freshness analysis using a thick-film array of electrodes," Microchimica Acta, vol. 163, no. 1-2, pp. 121-129, 2008.

[16] J. B. Raoof, R. Ojani, and S. Rashid-Nadimi, "Preparation of polypyrrole/ferrocyanide films modified carbon paste electrode and its application on the electrocatalytic determination of ascorbic acid," Electrochimica Acta, vol. 49, no. 2, pp. 271-280, 2004.

[17] S. Shahrokhian, M. Ghalkhani, and M. K. Amini, "Application of carbon-paste electrode modified with iron phthalocyanine for voltammetric determination of epinephrine in the presence of ascorbic acid and uric acid," Sensors and Actuators B, vol. 137, no. 2, pp. 669-675, 2009.

[18] H. R. Zare, N. Nasirizadeh, and M. Mazloum Ardakani, "Electrochemical properties of a tetrabromo-p-benzoquinone modified carbon paste electrode. Application to the simultaneous determination of ascorbic acid, dopamine and uric acid," Journal of Electroanalytical Chemistry, vol. 577, no. 1, pp. 25-33, 2005.

[19] M. Musameh, J. Wang, A. Merkoci, and Y. Lin, "Low-potential stable NADH detection at carbon-nanotube-modified glassy carbon electrodes," Electrochemistry Communications, vol. 4, no. 10, pp. 743-746, 2002.

[20] S. Wei, W. Dandan, G. Ruifang, and J. Kui, "Direct electrochemistry and electrocatalysis of hemoglobin in sodium alginate film on a BMIMPF6 modified carbon paste electrode," Electrochemistry Communications, vol. 9, no. 5, pp. 1159-1164, 2007.

[21] A. Salimi, R. G. Compton, and R. Hallaj, "Glucose biosensor prepared by glucose oxidase encapsulated sol-gel and carbonnanotube-modified basal plane pyrolytic graphite electrode," Analytical Biochemistry, vol. 333, no. 1, pp. 49-56, 2004. 
[22] A. Duran, M. Tuzen, and M. Soylak, "Preconcentration of some trace elements via using multiwalled carbon nanotubes as solid phase extraction adsorbent," Journal of Hazardous Materials, vol. 169, no. 1-3, pp. 466-471, 2009.

[23] M. Tuzen, K. O. Saygi, C. Usta, and M. Soylak, "Pseudomonas aeruginosa immobilized multiwalled carbon nanotubes as biosorbent for heavy metal ions," Bioresource Technology, vol. 99, no. 6, pp. 1563-1570, 2008.

[24] M. Tuzen, K. O. Saygi, and M. Soylak, "Solid phase extraction of heavy metal ions in environmental samples on multiwalled carbon nanotubes," Journal of Hazardous Materials, vol. 152, no. 2, pp. 632-639, 2008.

[25] M. Tuzen and M. Soylak, "Multiwalled carbon nanotubes for speciation of chromium in environmental samples," Journal of Hazardous Materials, vol. 147, no. 1-2, pp. 219-225, 2007.

[26] D. Odaci, A. Telefoncu, and S. Timur, "Pyranose oxidase biosensor based on carbon nanotube (CNT)-modified carbon paste electrodes," Sensors and Actuators B, vol. 132, no. 1, pp. 159-165, 2008.

[27] M. R. Ganjali, P. Norouzi, F. Faridbod, M. Yousefi, L. Naji, and M. Salavati-Niasari, "Perchlorate-selective membrane sensors based on two nickel-hexaazamacrocycle complexes," Sensors and Actuators B, vol. 120, no. 2, pp. 494-499, 2007.

[28] P. R. Buck and E. Lindner, "Recommendations for nomenclature of ionselective electrodes," Pure and Applied Chemistry, vol. 66, no. 12, p. 2527, 1994.

[29] Y. Umezawa, K. Umezawa, N. Hamada et al., "Recommendations for nomenclature of Ion-selective electrodes," Pure and Applied Chemistry, vol. 48, no. 1, pp. 127-132, 1976.

[30] R. Li, X. Chang, Z. Li et al., "Multiwalled carbon nanotubes modified with 2-aminobenzothiazole modified for uniquely selective solid-phase extraction and determination of $\mathrm{Pb}$ (II) ion in water samples," Microchimica Acta, vol. 172, no. 3-4, pp. 269-276, 2011. 

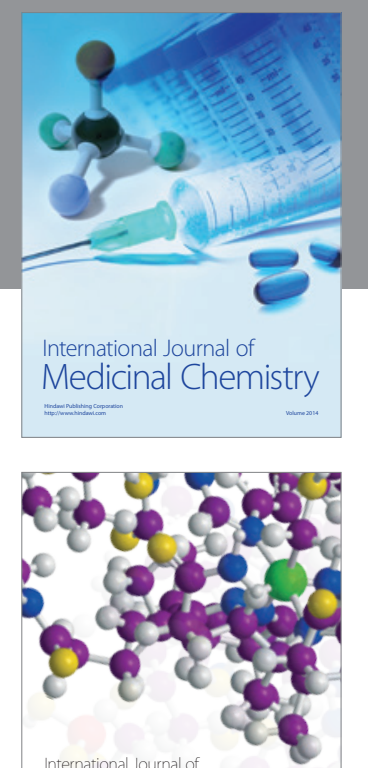

\section{Carbohydrate} Chemistry

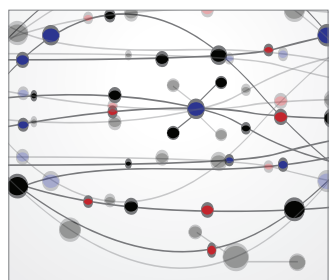

The Scientific World Journal
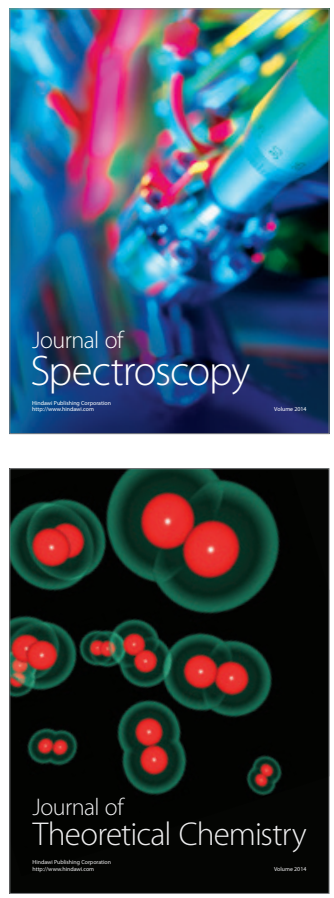
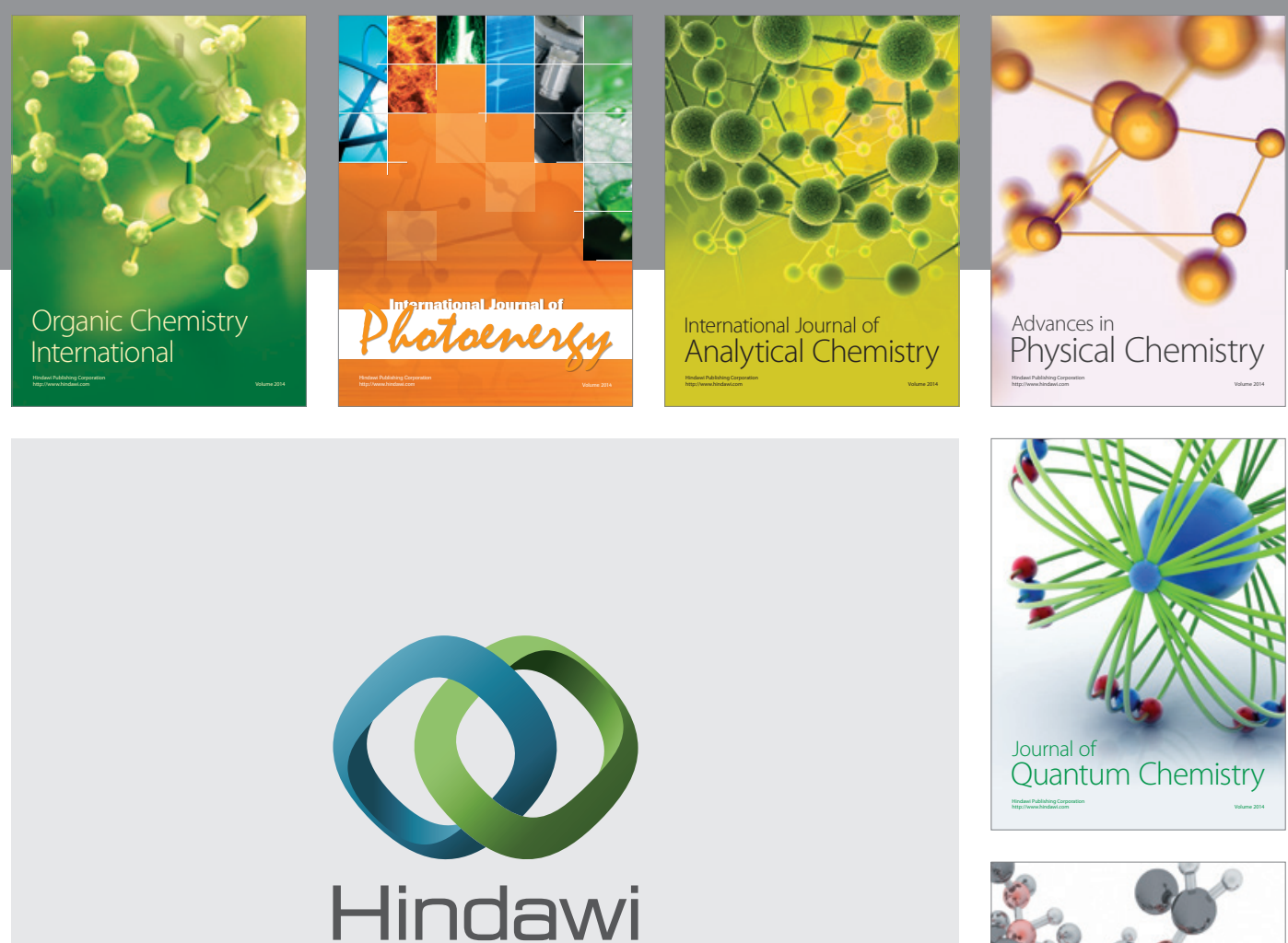

Submit your manuscripts at

http://www.hindawi.com

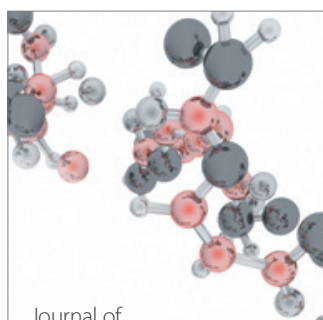

Analytical Methods

in Chemistry

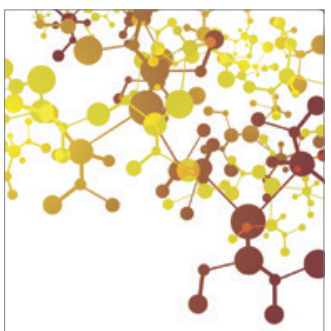

Journal of

Applied Chemistry

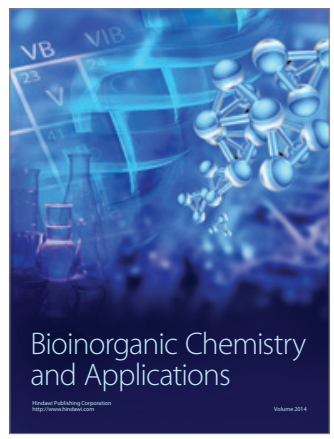

Inorganic Chemistry
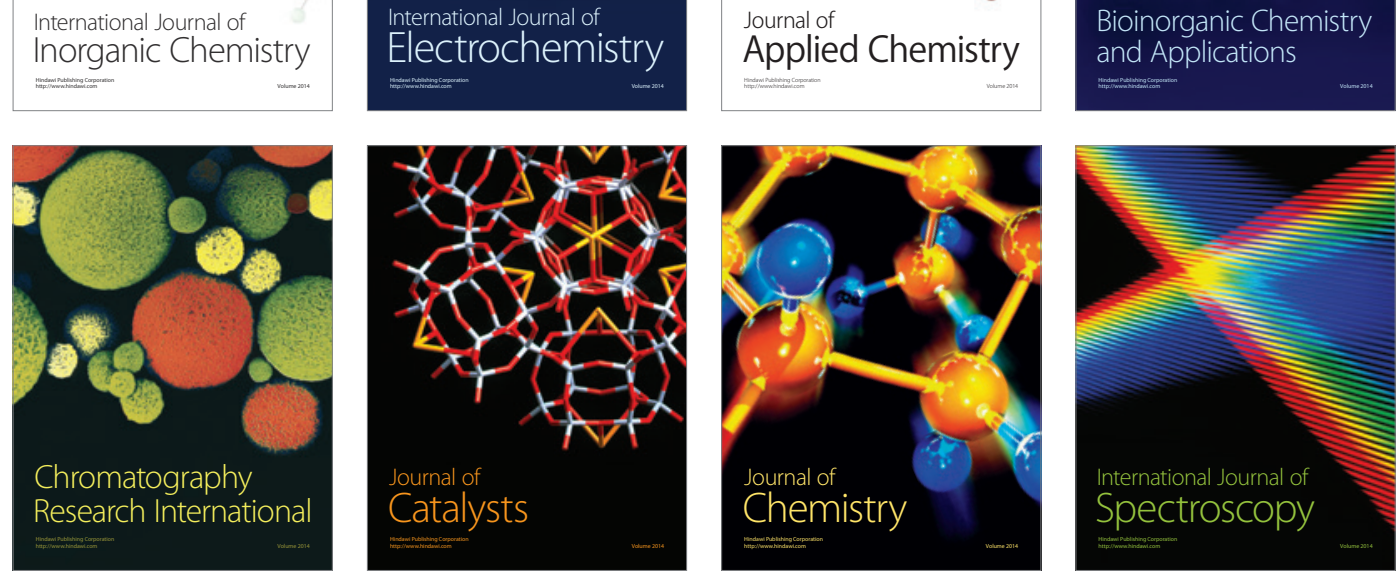